\title{
Influence of higher order modes on angled-facet amplifiers
}

\author{
Wang, Z.; Mikkelsen, B.; Stubkjær, Kristian
}

Published in:

I E E E Photonics Technology Letters

Link to article, DOI:

$10.1109 / 68.82114$

Publication date:

1991

Document Version

Publisher's PDF, also known as Version of record

Link back to DTU Orbit

Citation (APA):

Wang, Z., Mikkelsen, B., \& Stubkjær, K. (1991). Influence of higher order modes on angled-facet amplifiers. I E E E Photonics Technology Letters, 3(4), 366-368. https://doi.org/10.1109/68.82114

\section{General rights}

Copyright and moral rights for the publications made accessible in the public portal are retained by the authors and/or other copyright owners and it is a condition of accessing publications that users recognise and abide by the legal requirements associated with these rights.

- Users may download and print one copy of any publication from the public portal for the purpose of private study or research.

- You may not further distribute the material or use it for any profit-making activity or commercial gain

- You may freely distribute the URL identifying the publication in the public portal

If you believe that this document breaches copyright please contact us providing details, and we will remove access to the work immediately and investigate your claim 


\title{
Influence of Higher Order Modes on Angled-Facet Amplifiers
}

\author{
Z. Wang, B. Mikkelsen, and K. E. Stubkjaer
}

\begin{abstract}
The influence of the first-order mode on the residual reflectivity of angled-facet amplifiers is analyzed. For a $7^{\circ}$ angled-facet ridge waveguide amplifier with a single-layer $A R$ coating, a gain ripple lower than $1 \mathrm{~dB}$ at $25 \mathrm{~dB}$ gain can be obtained independent of the polarization, even in the presence of a first-order mode with a $15 \mathrm{~dB}$ gain. But the tolerances for the thickness and refractive index of the $A R$ coating are reduced by a factor of three compared to operation in the fundamental mode only. The influence of the higher order mode can virtually be suppressed by increasing the facet angles to $10^{\circ}$.
\end{abstract}

\section{INTRODUCTION}

A NGLED-FACET amplifiers are of increasing interest due to their inherently low modal reflectivity, and good performance has been obtained for angled-facet amplifiers with both $7^{\circ}$ and $10^{\circ}$ facet angles [1]-[3]. It is well known that for a given facet angle, a wider active region results in a lower modal reflectivity; however, this wide active region can also lead to the presence of the first-order mode [2]. The influence of the higher order modes on the gain ripple of straight facet amplifiers was discussed in [4]. Here we will analyze the influence of the first-order mode on the gain ripple of angled-facet amplifiers as a function of the facet angle.

\section{ANALYSIS}

Two-dimensional models are sufficient for calculating the mode coupling of a straight-facet amplifier due to the relatively large beamwidth in the junction plane [5]. In the case of angled-facet amplifiers, the waveguide is tilted in the junction plane and a three-dimensional model is necessary. Here we have used a previously developed three-dimensional model [6] to investigate the modal coupling at the facets of the amplifier. The model accounts for both the amplitude and phase changes of the light reflected from the angled facet. The fields of the fundamental and the first-order modes are assumed to follow Hermite-Gaussian functions. This has proved to be an acceptable approximation by comparing the calculated and the measured far fields of the angled devices [7]. With a reference plane coincident with the facets (see Fig. 1), the plane wave spectra of the fields of the fundamental mode $F_{0}(\alpha, \beta)$ and the first-order mode $F_{1}(\alpha, \beta)$ are

Manuscript received December 26, 1990; revised February 13, 1991. This work was supported in part under RACE Project 1027.

The authors are with the Center for Broadband Telecommunications, Electromagnetics Institute, Technical University of Denmark, DK-2800, Lyngby, Denmark.

IEEE Log Number 9144478.

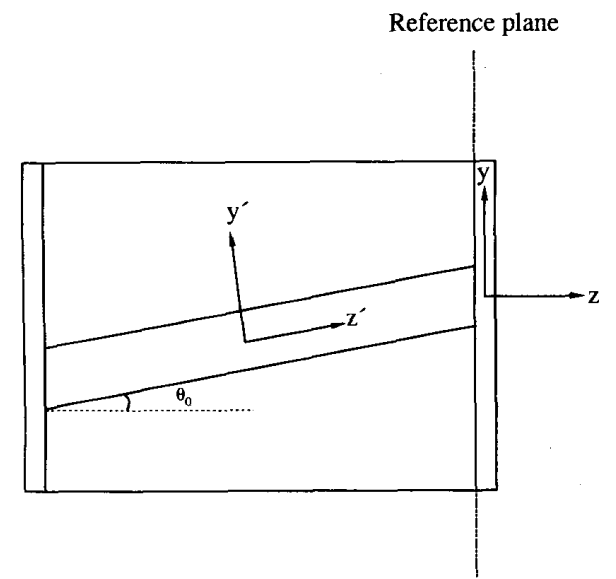

Fig. 1. Schematic of an angled-facet amplifier.

given by

$\begin{aligned} & F_{0}(\alpha, \beta)=\frac{\sqrt{\pi} W_{x} W_{y}}{\lambda^{2} \cos \theta_{0}} \\ & \cdot \exp \left(\frac{-\pi^{2} n_{1}^{2}\left(W_{y}^{2}\left(\gamma \sin \theta_{0}+\beta \cos \theta_{0}\right)^{2}+\alpha^{2} W_{x}^{2}\right)}{\lambda^{2}}\right)\end{aligned}$

$F_{1}(\alpha, \beta)$

$=\frac{\sqrt{2} \pi n_{1} W_{y}}{\lambda}\left(\gamma \sin \theta_{0}+\beta \cos \theta_{0}\right) F_{0}(\alpha, \beta) \exp \left(j \frac{\pi}{2}\right)$

$W_{x}$ and $W_{y}$ are the $1 / \mathrm{e}$-widths of the field inside the cavity; $\lambda$ is the wavelength; $\alpha, \beta$, and $\gamma$ are the directional cosines in the coordinate system $x y z$; and $\theta_{0}$ is the angle of the waveguide to the facet normal. The effective refractive index $n_{1}$ is approximately the same for both the fundamental mode and the first-order mode. The modal coupling taking place at the facet from the incident mode $l$ to the mode $m$ is given by

$$
\begin{gathered}
K_{l m}=\frac{1}{C_{l} C_{m}} \\
\cdot\left|\iint_{-\infty}^{+\infty} F_{l}(\alpha, \beta) Q(\alpha, \beta) F_{m}(\alpha, \beta) d \alpha d \beta\right|^{2} \\
l, m=0,1
\end{gathered}
$$




$$
C_{l}=\iint_{-\infty}^{+\infty} q(\alpha, \beta)\left|F_{l}(\alpha, \beta)\right|^{2} d \alpha d \beta \quad l=0,1
$$

where $q(\alpha, \beta)$ is given by $\left(1-\beta^{2}\right) / \gamma$ for the TE mode, and $\left(1-\alpha^{2}\right) / \gamma$ for the TM mode. The coupling factor $Q(\alpha, \beta)$ is given by [8]

$$
Q(\alpha, \beta)=\left\{\begin{array}{cr}
R_{||}\left(1+\frac{\beta^{2}}{\gamma^{2}}-\frac{\alpha^{2}}{\alpha^{2}+\beta^{2}}\right) & \\
+R_{\perp} \frac{\alpha^{2}}{\alpha^{2}+\beta^{2}} & \text { TE mode } \\
R_{||}\left(1+\frac{\alpha^{2}}{\gamma^{2}}-\frac{\beta^{2}}{\alpha^{2}+\beta^{2}}\right) & \\
+R_{\perp} \frac{\beta^{2}}{\alpha^{2}+\beta^{2}} & \text { TM mode }
\end{array}\right.
$$

where $R_{\|}$and $R_{\perp}$ are the Fresnel reflectivities.

The gain ripple $\Delta G$ of the amplifier is given by [4]

$$
\Delta G(\mathrm{~dB})=20 \log _{10}\left|\frac{1+A}{1-A}\right|
$$

where $A$ is given by

$$
A=\sum_{i, j=0,1} \sqrt{K_{0 i} K_{j 0} G_{i} G_{j}} \exp \left(j \phi_{i j}\right) .
$$

$G_{i}$ and $G_{j}$ are the modal single-pass gains, and $\phi_{i j}$ is the difference of the single-pass phase shifts of modes $i$ and $j$. To consider the worst case, we take $\phi_{i j}=0$ in our calculations. The results obtained from this model are shown in the following.

\section{RESULTS}

The gain ripple is used to assess the quality of the antireflection (AR)-coated facets of an amplifier; and the coating tolerances for which the gain ripple is lower than a given level can be taken as a measure for the applicability of the AR-coating technique investigated. It should be added that the bandwidth of the AR coating is increasing with the tolerances, so in order to utilize the full transmission bandwidth, large coating tolerances are also desirable. Both the gain ripple and the coating tolerances in the presence of higher order modes can be found from (6) and (7). For the angled-facet ridge waveguide amplifier under consideration, we use beam widths $W_{x}$ and $W_{y}$ of 0.6 and $1.3 \mu \mathrm{m}$ as determined from measurements of the far-field patterns of actual devices [7]. The operating wavelength is $1.55 \mu \mathrm{m}$ and the effective index is 3.28 . We assume a single-pass gain for the fundamental mode of $25 \mathrm{~dB}$, and a $10 \mathrm{~dB}$ lower gain for the first-order mode. This assumption is considered conservative since measurements of the far-field patterns did not indicate the presence of higher order modes.

Contour plots for a $1 \mathrm{~dB}$ gain ripple are shown in Fig. 2 in the thickness versus refractive index space of a single-layer AR coating applied to $a 7^{\circ}$ angled-facet amplifier. Results for

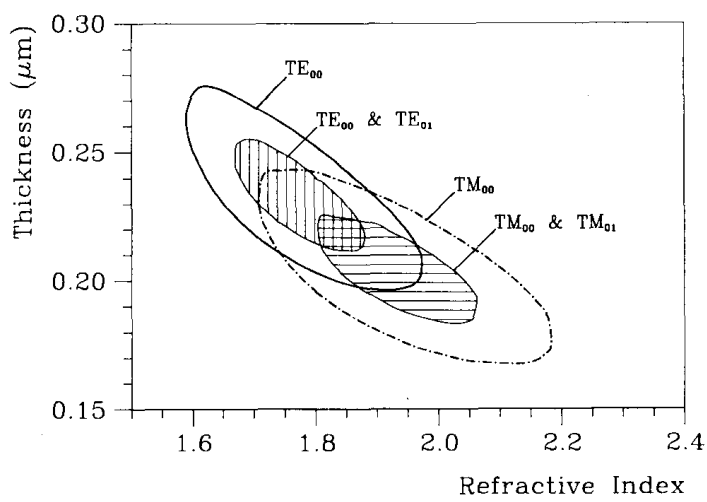

Fig. 2. Contour plots for $1 \mathrm{~dB}$ gain ripple in the refractive index versus coating thickness space of a single-layer AR coating. The facet angle is $\theta_{0}=7^{\circ}$, and results without and with the first-order mode are shown. $G_{0}=25 \mathrm{~dB}$ and $G_{1}=15 \mathrm{~dB}$.

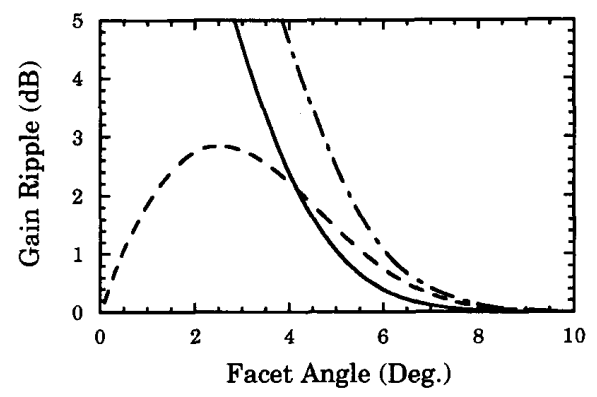

Fig. 3. Gain ripple versus facet angle for operation in the $T E_{00}$ mode $(-)$, the $\mathrm{TE}_{01}$ mode $(-\cdots)$, and both the $\left.\mathrm{TE}_{00}\right)$ and $\mathrm{TE}_{01}$ modes $(\cdots,-)$. Modal gains are as in Fig. 2.

both polarizations are shown with and without the presence of the first-order mode. A $1 \mathrm{~dB}$ ripple at $25 \mathrm{~dB}$ gain corresponds to a residual reflectivity of $10^{-4}$ for the singlemode case and is considered acceptable for practical applications. The overlap of the contour plots for TE and TM modes shows that for a polarization independent low ripple, the tolerances for the thickness and the refractive index of the coating layer are $400 \AA$ and 0.2 in the case of fundamental mode operation. In the presence of the first-order mode, the tolerances are reduced by a factor of three, so even a weak higher order mode will influence the coating tolerances significantly.

In order to get low gain ripple irrespective of the polarization, the thickness and the refractive index of the coating should be $0.22 \mu \mathrm{m}$ and 1.84 according to Fig. 2. For this coating, the calculated gain ripples due to the fundamental mode, the first-order mode, and both modes are seen in Fig. 3 versus the facet angle $\theta_{0}$ of the amplifier. Again, gains of the fundamental and the first-order modes are assumed to be 25 and $15 \mathrm{~dB}$. The gain ripple is mainly due to the first-order mode for $\theta_{0}>4^{\circ}$ because of high coupling coefficients $K_{11}$ and $K_{01}$ [see (3)] related to the first-order mode. However, the gain ripple is reduced to less than $0.2 \mathrm{~dB}$ for facet angles beyond $8^{\circ}$.

The gain of the first-order mode can vary significantly 


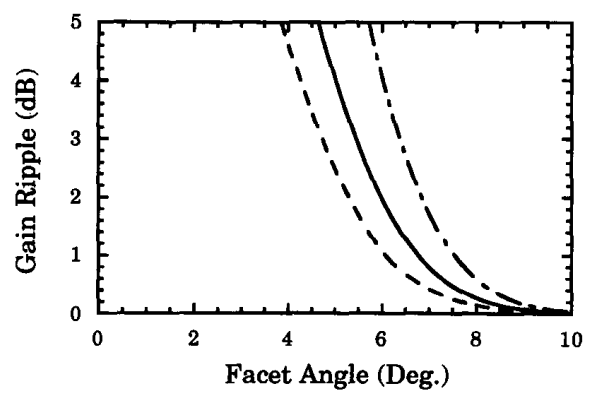

Fig. 4. Gain ripple due to both $T E_{00}$ and $T E_{01}$ modes versus the facet angle. $G_{1}=15 \mathrm{~dB}(-\cdots), 20 \mathrm{~dB}(-)$, and $25 \mathrm{~dB}(\cdots \cdot \cdot \cdot \cdot), G_{0}=25 \mathrm{~dB}$.

depending on the waveguide structure [9]. To study the influence of the first-order mode, Fig. 4 gives the total gain ripple as a function of facet angle for gains of the first-order mode of 15,20 , and $25 \mathrm{~dB}$. The gain of the fundamental mode is maintained at $25 \mathrm{~dB}$. As seen, even for equal gains of the two modes, the angled facet can suppress the ripple to less than $0.2 \mathrm{~dB}$ for facet angles of $10^{\circ}$. It should be noted that the $10^{\circ}$ facet angle will distort the far-field pattern slightly, but the resulting excess coupling losses to optimized tapered-lens-ended fibers will be lower than $0.5 \mathrm{~dB}$ [8].

\section{CONCLUSION}

Coating tolerances for a $1 \mathrm{~dB}$ gain ripple at $25 \mathrm{~dB}$ gain have been calculated for a $7^{\circ}$ angled-facet amplifier with a single-layer AR coating. Even in the presence of a first-order mode with a $10 \mathrm{~dB}$ lower gain compared to the fundamental mode, a polarization independent gain ripple of less than 1 $\mathrm{dB}$ is possible, but the tolerances for the coating are tight. However, the ripple will decrease with the facet angle, and for facet angles of $10^{\circ}$ the gain ripple is lower than $0.2 \mathrm{~dB}$ even if the gain of the first-order mode is comparable to that of the fundamental mode.

\section{ACKNOWLEDGMENT}

We thank Dr. J. E. A. Whiteaway of STC Technologies, Harlow, England, for results on gain in the ridge waveguide structure.

\section{REFERENCES}

[1] A. J. Collar et al., in "Fabrication and performance of $\lambda=1.5 \mu \mathrm{m}$ angle facet amplifiers," Tech. Dig. 11th IEEE Int. Semiconductor Laser Conf., Boston, MA, Aug. 29, 1988, Postdeadline Paper PD-6.

[2] C. E. Zah et al., "Fabrication and performance of $1.5 \mu \mathrm{m}$ GaInAsP traveling-wave laser amplifier with facet angle," Electron. Lett., vol. 23, pp. 990-992, 1988.

[3] A. J. Collar et al., "Low residual reflectivity of angled-facet semiconductor laser amplifier," IEEE Photon. Technol. Lett., vol. 2 pp. 553-555, Aug. 1990

[4] C. Vassalo, "Gain ripple minimisation and higher-order modes in semiconductor optical amplifiers," Electron. Lett., vol. 25, pp. 789-791, 1989.

[5] For example, G. Eisenstein, "Theoretical design of single layer antireflection coating on laser facet," Bell Syst. Tech. J., vol. 24, pp. $357-364,1984$

[6] Z. Wang et al., "Single layer coating for angled facet amplifier," Electron. Lett., vol. 25, pp. 1139-1141, 1989.

[7] Z. Wang et al., "Coupling between angled-facet amplifiers and tapered lens-ended fibers," J. Lightwave Technol., pp. 49-55, Jan. 1991.

[8] R. H. Clarke, "Theory of reflection from antireflection coatings," Bell Syst. Tech. J., pp. 2885-2890, vol. 62, 1983.

[9] J. E. A. Whiteaway, private communication. 